\title{
The Existence of Endophytic Actinobacteria from Rhododendron zoelleri Revealed by Culture-Dependent and Culture-Independent Approaches
}

\author{
Yulin Lestari ${ }^{1,3^{*}}$, Lia Aseptin Murdini², Dedy Duryadi Solihin ${ }^{1}$ \\ 1 Department of Biology, Faculty of Mathematics and Natural Sciences, Bogor Agricultural University, Bogor, Indonesia \\ ${ }^{2}$ Graduate School, Bogor Agricultural University, IPB Dramaga, Bogor, Indonesia \\ ${ }^{3}$ Tropical Biopharmaca Research Center, Bogor Agricultural University, Campus IPB Taman Kencana, Bogor, Indonesia
}

\section{ARTICLE INFO}

Article history:

Received October 10, 2017

Received in revised form January 23, 2018

Accepted February 2, 2018

\section{KEYWORDS:}

actinobacteria,

$D G G E$,

endophyte,

metagenomic,

R. zoelleri,

$16 S$ rRNA gene

\begin{abstract}
Endophytic actinobacteria from medicinal plant may play a significant role in producing bioactive compounds. The information regarding their diversity is an important. Rhododendrons are traditionally used for treating human disorders. One of the selected Rhododendron used in this study was $R$. zoelleri from Papua origin, which has been conserved and grown in Cibodas Botanical Garden, West Java, Indonesia. The aim of this study was to assess the existence of endophytic actinobacteria from $R$. zoelleri based on a culture-dependent and their community structure based on a culture-independent approach. Culturable actinobacteria were isolated and cultured on HV medium. Polymerase Chain Reaction-Denaturing Gradient Gel Electrophoresis (PCR-DGGE) targeting the metagenomic 16S rRNA was used to analyse the structure of the actinobacterial community. Six culturable endophytic actinobacteria (200 cfu/g fresh weight) from $R$. zoelleri were successfully isolated, three isolates from leaf, and the other isolates were obtained from stem. The six culturable isolates were RZP 1.3, RZP 1.1, RZP 2.2, RZPB 1.1, RZPB 7.1, RZPB 4.1. Based on their morphological characteristics, the endophytes have Streptomyces characters. The existence of Streptomyces spp. were also confirmed with molecular analysis based on $16 \mathrm{~S}$ rRNA gene. The phylogenetic analysis based on $16 \mathrm{~S}$ rRNA gene to the reference strains available in EzTaxon-e database showed that six isolates were closely related to $S$. djakartensis strains of NBRC $15409^{\mathrm{T}}(99.19 \%)$, S. tritolerans strains of DAS 165T(99.90\%), S. coelicoflavus strains of NBRC 15399T(99.59). However, they showed differences in morphological characteristics as compared with the reference strains. The metagenomic analysis of the DGGE profile based on $16 \mathrm{~S}$ rRNA gene showed the community structure of endophytic actinobacteria from $R$. zoelleri which was represented by 13 DGGE bands. The bands were closely related to Agromyces, Gordonia, Microbacterium, Micromonospora, Propionibacterium, Saccharomonospora, Streptomyces which have 93.18\%-100\% similarity. Based on the data, it showed diversity of endophytic actinobacteria from $R$. zoelleri which may be further assess for their novelty and bioprospecting.
\end{abstract}

\section{Introduction}

Rhododendron zoelleri is a species of subgenus vireya, grouped in family of Ericacea, $R$. zoelleri grow in mountain forests with a height of 2000 above sea level (Argent 2006), origin from Papua, and has been collected in Cibodas Botanical Garden as a national plant conservation area in Indonesia. Species collection of Rhododendrons in Cibodas Botanical Gardens include R. sessilifolium,

\footnotetext{
* Corresponding Author

E-mail Address: yulinlestari@gmail.com

Copyright (C2018 Institut Pertanian Bogor
}

Rhododendron sp., R. multicollor, R. javanicum, R. zoelleri, each comes from Sumatera, Bengkulu, Jambi, Java, and Papua, respectively, and $R$. hybrid ( $R$. javanicum and $R$. sessilifolium). Rhododendron has long been used as a traditional medicine, for example $R$. brachycarpum was used to treat diabetes and hypertension in Korea (Choi et al. 2012). R. groenlandicum was used to treat diabetes in Canada (Leduc et al. 2006). R. tomentosum was also used for the treatment of diabetes in China, Korea and Japan (Tam et al. 2011). Rhododendron was reported to produce bioactive compounds e.g. flavonoid and terpenoid (Qiang et al. 2011). The bioactive compounds 
from Rhododendron are presumably related to the presence and diversity of endophytic microbes residing in the plant tissue (Tan and Zou 2001), without causing disease in host plant (Schulz et al. 1993). Endophytic actinobacteria was known as a wide range producer of bioactive compounds (Zhao et al. 2011). Endophytic actinobacteria may have a significant contribution to the production of bioactive compounds in medicinal plants (Pujiyanto et al. 2012). Actinobacteria is a grampositive bacteria within the high $\mathrm{G}+\mathrm{C}$ content more than 55\% (Emley and Stackebrandt 1994).

The information regarding diversity of endophytic actinobacteria from $R$. zoelleri has not been reported. The work is very important to explore endophytic actinobacteria $R$. zoelleri, as source of a germ plasm which can be used for further characterization on their potential utilization. The diversity of culturable actinobacteria can be obtained by cultivating actinobacteria on isolation medium under laboratory conditions, and the metagenomic approach which provide diversity based on genomic data. The genomic data may give more insight information regarding endophytic actinobacteria from $R$. zoelleri, since more than $99 \%$ microbes in the environtment can not be cultivated in a medium (unculturable) (Kimura 2006). The aim of this study was to investigate the diversity of culturable and unculturable endophytic actinobacteria from $R$. zoelleri using combination of a culture-dependent by cultivation in HV medium and a culture-independent approach by PCR-DGGE based on 16S rRNA gene.

\section{Materials and Methods}

\subsection{Materials}

$R$. zoelleri as the plant samples were originally collected from Papua in 2009 and now grown in Cibodas Botanical Garden, Indonesia. The samples were selected from healthy plants.

\subsection{Methods}

\subsubsection{Isolation and Morphological Characterisation of Culturable Actinobacteria}

Culturable endophytic actinobacteria was isolated and cultured on Humic Acid Vitamin B Agar (HV Agar) (Hayakawa and Nonomura 1987). About $1 \mathrm{~g}$ of sample of leave and stem were washed with sterile distilled water then surfaces sterilized by soaking in 70\% alcohol for $1 \mathrm{~min}$, folowed by $1 \%$ hypochlorite solution for $5 \mathrm{~min}$, and $70 \%$ alcohol for $1 \mathrm{~min}$, and finally rinsed with sterile distilled water. Then the sterilized samples were crushed and serial dilutions up to $10^{-3}$ were carried out. Each of suspension $(0.1 \mathrm{~mL})$ of sample was taken from $10^{-1}, 10^{-2}$, and $10^{-3}$ dilutions, spread on HV Agar, and then incubated at room temperature for 4 to 8 weeks (Coombs and Franco 2003). Actinobacterial colonies were purified using International Streptomyces Project 2
(ISP2). The colonies were morphologically characterized based on macroscopic (pigmentation, colour of colony and growth in four different media, i.e. ISP 2, ISP 3, ISP 4, Yeast Starch Agar (YSA)) character, and microscopic (aerial hypha type) observations using an Olympus Optilab microscope at 400x magnification.

\subsubsection{Genomic DNA Isolation from Culturable Actinobacteria}

Isolation of actinobacterial genomic DNA was performed according to the Geneaid Genomic DNA Mini Kit protocol(Blood/Cultured Cell). DNA concentration was measured using the NanoDrop 2000 spectrophotometer (Thermo Scientific, Wilmington, DE, USA).

\subsubsection{DNA Extraction from $\boldsymbol{R}$. zoelleri Tissues}

About $0.1 \mathrm{~g}$ of leave and stem of $R$. zoelleri were crushed into powder in a liquid nitrogen, then the total DNA was extracted according to protocol by Genomic DNA Mini Kit, Plant (Geneaid, Shijr, TPE, TW). The purity and the quantity of the extract were measured using NanoDrop 2000 (Thermo Scientific, Wilmington, DE, USA).

\subsubsection{The 16S rRNA GeneAmplification of Culturable and Unculturable Endophytic Actinobacteria}

Genomic DNA was amplified by polymerase chain reaction (PCR) using the T1-thermocycler (Biometra, Goettingen, Germany). Genomic DNA was used as the template for amplification using two 16S rRNA gene primers specific for actinobacteria, i.e. 27F (5'-AGAGTTTGATCCTGGCTCAG-3') and 16Sact1114R (5'-GAGTTGACCCCGGCRGT-3') (Martina et al. 2008). The $25 \mu \mathrm{L}$ reaction volume consisted of $12.5 \mu \mathrm{L}$ GoTaq Green Master Mix $2 \times, 2.5 \mu \mathrm{L}$ of each primer $(10 \mathrm{pmol})$, $2.5 \mu \mathrm{L}$ template DNA ( $100 \mathrm{ng} / \mu \mathrm{L})$ and $7.5 \mu \mathrm{L}$ nuclease free water. PCR condition were as follows: 2 min predenaturation at $95^{\circ} \mathrm{C}, 30 \mathrm{sec}$ denaturation at $95^{\circ} \mathrm{C}, 45$ sec annealing at $55^{\circ} \mathrm{C}, 1 \mathrm{~min}$ elongation at $72^{\circ} \mathrm{C}, 5 \mathrm{~min}$ post elongation at $72^{\circ} \mathrm{C}$, and 15 min cooling at $4^{\circ} \mathrm{C}$ PCR was performed over 35 cycles and the products electrophorized on $1 \%$ agarose gel. A single DNA band per sample was observed in the G:BOX gel documentation system (Syngene, Frederick, MD, USA) to observe the \pm 1087 bp target DNA band. The product of first phase PCR was used as template DNA for the second phase PCR using the universal primer for bacteria, i.e. P338GC (5'CGCCCGCCGCGCGCGGCGGGCGGGGCGGGGGCA CGGGGGGACTCCTACGGGAGGCAGCAG-3')and P518R (5'-ATTAC CGCGGCTGCTGG-3') (Overeas et al. 1997). A PCR reaction volume of $25 \mu \mathrm{L}$ consisted of $12.5 \mu \mathrm{L}$ GoTaq Green Master Mix 2× (Promega, Madison, WI, USA), $1.25 \mu \mathrm{L}$ of each primer (10 pmol), $1.25 \mu \mathrm{L}$ of the product of first phase PCR, and $9 \mu \mathrm{L}$ nuclease free water. PCR for the 16S rRNA gene was conducted over 30 cycles that consisted of $5 \mathrm{~min}$ predenaturation at $94^{\circ} \mathrm{C}, 30 \mathrm{sec}$ denaturation at $92^{\circ} \mathrm{C}, 30 \mathrm{sec}$ 
annealing at $58^{\circ} \mathrm{C}, 1 \mathrm{~min}$ elongation at $72^{\circ} \mathrm{C}$, and $5 \mathrm{~min}$ post elongation at $72^{\circ} \mathrm{C}$. The PCR products $(5 \mu \mathrm{L})$ were run on $1 \%$ agarose gel for $45 \mathrm{~min}$ at $80 \mathrm{~V}$. The electrophoresis results were visualized after Ethidium Bromide (EtBr) staining and 180 bp bands were observed on the G:BOX gel documentation system (Syngene, Frederick, MD, USA).

\subsubsection{DGGE Analysis of the $16 \mathrm{~S}$ rRNA Gene}

The PCR product of $16 \mathrm{~S}$ rRNA gene was run on to a $0.75 \mathrm{~mm}$ vertical gel containing $8 \%(\mathrm{w} / \mathrm{v})$ polyacrylamide [acrylamide-bisacrylamide (37.5: 1)] in $1 \times$ Tris-acetate-EDTA (TAE). The denaturant gradient concentrations used were $30 \%$ and $70 \%$ (100\% denaturant in accordance with $7 \mathrm{M}$ urea and $40 \%$ formamide). Electrophoresis was conducted for $6 \mathrm{~h}$ at $60^{\circ} \mathrm{C}, 150 \mathrm{~V}$ using the D Code Universal Mutation Detection System (Bio-Rad, Hercules, CA, USA). The electrophoresis gel was stained with $\mathrm{EtBr}$ for $30 \mathrm{~min}$, followed by rinsing with $500 \mathrm{~mL}$ of $1 \times$ TAE buffer before observing the bands in the G:BOX gel documentation system (Syngene, Frederick, MD, USA). DGGE band was analyzed by using CLIQS 1D Pro software to estimate the total bands. Separated bands were cut using a sterile scalpel and placed into micro tubes containing $100 \mu \mathrm{L} \mathrm{ddH_{2 }} \mathrm{O}$. The products of DGGE were incubated at $4^{\circ} \mathrm{C}$ overnight, and then incubated again at $60^{\circ} \mathrm{C}$ for $2 \mathrm{~h}$, following the conditions and primers used in the second phase PCR but without the GC-clamp (Muyzer and Uitterlinden 1993).

\subsubsection{Diversity and Abundance Analysis}

Relatif abundance of endophytic actinobacterial community was analysed based on the volume of DGGE bands using CLIQS 1D Pro, to calculate the Operation Taxonomic Unit (OTU). Diversity index was analysed by Shannon-Wiener index $\left(\mathrm{H}^{\prime}\right)$ using past 3 software with formula:

$$
\mathrm{H}^{\prime}=-\sum(\text { pi log pi) }
$$

$\mathrm{H}^{\prime}=$ diversity index, $\mathrm{pi}=$ ratio of one individuals number to the total number of samples in the plot (n/N) (Hill et al. 2003).

\subsubsection{Bioinformatic Analysis and Construction of Phylogenetic Tree}

The PCR products of the 16S rRNA gene of culturable and unculturable endophytic actinobacteria $R$. zoelleri were sequenced following standard protocols of DNA sequencing (ABI PRISM 3100). The sequencing results were compared to those of reference strains available in the EzTaxon (https://www.ezbiocloud. net/). Phylogenetic analysis was conducted using MEGA 6 software, and the phylogenetic tree was constructed using a 1000 replication-bootstrap analysis and the neighbour-joining method (Tamura et al. 2011).

\section{Results}

\subsection{Diversity of Culturable Endophytic Actinobacteria}

Total of 6 isolates (200 cfu/g fresh weight) of endophytic actinobacteria were successfully isolated from $R$. zoelleri, 3 isolates from leaves and stems respectivelly. Isolation using $\mathrm{HV}$ agar medium and purified using ISP 2 medium. The collected endophytic actinobacteria showed to vary based on morphological characteristics (Figure 1 and Table 1 ).

The 6 isolates ( $200 \mathrm{cfu} / \mathrm{g}$ fresh weight) endophytic actinobacteria were grown in ISP 2 medium, showed morphological colony diversity, and based on this morphological characteristics of substrate mycelia color, aerial mycelia, medium pigmentation, and spore chain morphology. These morhological characters close to the groupped of Streptomyces (Shirling and Gottlieb 1966). The vary of hypa type based on spore chain of the isolate were retinaculum-apertum for RZP 1.3 and RZP 1.1, spira for RZP 2.2, RZPB 1.1, and RZPB 7.1, biverticillus-spira for RZPB 4.1 (Figure 1 and Table 1).

Morphological characteristics of endophytic actinobacteria from $R$. zoelleri were known by growing isolates on four different media (ISP 2, ISP 3, ISP 4, YSA). All isolates have abundant growth on ISP 2, ISP 3 , ISP 4 and YSA medium, but RZPB 7.1 showed moderate growth in four media. The aerial mycelium had wide range of colors on different media (ISP 2, ISP 3, ISP

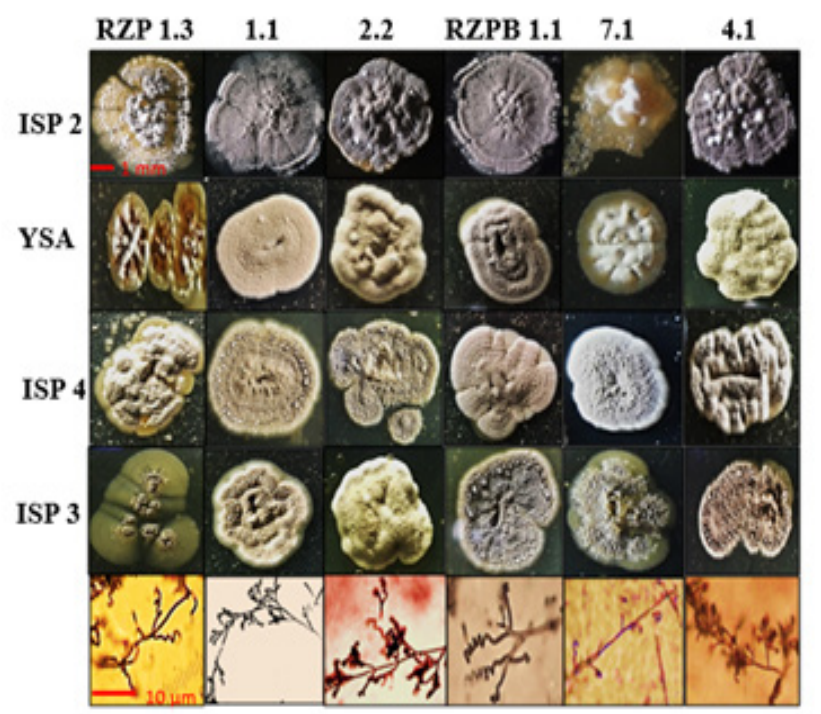

Figure 1. Morphological characteristics (macroscopic and microscopic) of culturable endophytic actinobacteria for 14 days incubation, microscopic using light microscope (Olympus) 400x magnification 
Table 1. Morphological characteristics of culturable endophytic actinobacteria on diferent medium for 14 days incubation

\begin{tabular}{|c|c|c|c|c|c|c|}
\hline Medium & Isolate code & $\begin{array}{l}\text { Aerial } \\
\text { mycelium }\end{array}$ & $\begin{array}{l}\text { Substrat } \\
\text { mycelium }\end{array}$ & Soluble pigment & Growth & Spore chain \\
\hline \multirow[t]{6}{*}{ YMA } & RZP 1.3 & Brownish gray & Brownish gray & Chocolate & Abundant & Retinaculum-apertum \\
\hline & RZP 1.1 & Gray & Yellow & - & Abundant & Retinaculum-apertum \\
\hline & RZP 2.2 & Gray & Yellow & - & Abundant & Spira \\
\hline & RZPB 1.1 & Gray & Yellow & - & Abundant & Spira \\
\hline & RZPB 7.1 & White & Brownish white & - & Moderate & Spira \\
\hline & RZPB 4.1 & Gray & Yellow & - & Abundant & Biverticillus-Spira \\
\hline \multirow[t]{6}{*}{ YSA } & RZP 1.3 & Yellowish brown & Yellowish brown & - & Abundant & Retinaculum-apertum \\
\hline & RZP 1.1 & Light brown & Yellow & Chocolate & Abundant & Retinaculum-apertum \\
\hline & RZP 2.2 & Light brown & Yellow & - & Abundant & Spira \\
\hline & RZPB 1.1 & Gray & Yellow & & Abundant & Spira \\
\hline & RZPB 7.1 & White & Brownish white & - & Moderate & Spira \\
\hline & RZPB 4.1 & Greenish Chocolate & Yellow & & Abundant & Biverticillus-Spira \\
\hline \multirow[t]{6}{*}{ ISA } & RZP 1.3 & Light brown & Brownish white & Chocolate & Abundant & Retinaculum-apertum \\
\hline & RZP 1.1 & Light brown & Brownish white & - & Abundant & Retinaculum-apertum \\
\hline & RZP 2.2 & Light brown & Brownish white & - & Abundant & Spira \\
\hline & RZPB 1.1 & Light brown & Brownish white & - & Abundant & Spira \\
\hline & RZPB 7.1 & White & Brownish white & - & Moderate & Spira \\
\hline & RZPB 4.1 & Light brown & Brownish white & - & Abundant & Biverticillus-Spira \\
\hline \multirow[t]{6}{*}{$\mathrm{OA}$} & RZP 1.3 & Brownish gray & Brownish white & - & Abundant & Retinaculum-apertum \\
\hline & RZP 1.1 & Chocolate & Gray & - & Abundant & Retinaculum-apertum \\
\hline & RZP 2.2 & Greenish Chocolate & Gray & - & Abundant & Spira \\
\hline & RZPB 1.1 & Gray & Gray & - & Abundant & Spira \\
\hline & RZPB 7.1 & Gray & Brownish yellow & - & Moderate & Spira \\
\hline & RZPB 4.1 & Dark brown & Gray & - & Abundant & Biverticillus-Spira \\
\hline
\end{tabular}

RZP = Rododendron zoelleri Leaves Papua; RZPB = Rododendron zoelleri Stems Papua

4, YSA), e.g. brownish gray, gray, white, yellowishbrown, light brown, greenish chocolate, light brown, chocolate, dark brown, meanwhile substrate mycelium showed tohave yellowish brown, yellow, white brownish, gray, brownish yellow. The RZP 1.3 showed brown pigmentation on ISP 2, ISP 4, YSA media but not on ISP 3 medium, while the other isolates were not found to produce pigmentation in the tested media.

\subsection{Identification of Culturable Endophytic Actinobacteria Isolates Based on 16S rRNA Gene}

The 16S rRNA gene from the genomic DNA of six culturable isolates were successfuly amplified using $27 \mathrm{~F}$ and 16 Sact1114R primers with $\pm 1087 \mathrm{bp}$ DNA fragment as the target. The result of nucleotide sequencing of $16 \mathrm{~S}$ rRNA gene was aligned between the forward and reverse sequences, then corrected by the primer. All isolates have homology sequences with the genus of Streptomyces (Table 2).

The partial sequence ( $\pm 1087 \mathrm{bp}$ ) of 16S rRNA gene and phylogenetic analyses (Figure 2; Table 2) confirmed that RZP 1.1, RZP 2.2, RZPB 1.7, RZPB 4.1 closely related with $S$. tritolerans strain DAS $165^{\mathrm{T}}$ and showed high similarity by $99.90 \%$. Streptomyces tritolerans was isolated from dryland in India, and has been known for its potency as a producer of antibiotic compounds (Mangamuri et al. 2014). These isolates
(RZP 1.1, RZP 2.2, RZPB 1.7, RZPB 4.1) have similarity with $S$. tritolerans strain DAS $165^{\mathrm{T}}$ on both substrate and aerial mycelia, e.g. gray and yellow but have different spore chain e.g. retinaculum-apertum (RZP 1.1, RZP 2.2), spira (RZPB 1.7), retinaculum-apertum (RZPB 4.1) while S. tritolerans strain DAS $165^{\mathrm{T}}$ had straigh-flexous (Syed et al. 2007).

The RZP 1.3 was closely related with S. djakartensis strains of NBRC $15409^{\mathrm{T}}$ (99.19\%), as the type strain and not yet reported for its potency. RZP 1.3 had retinaculum-apertum of spore chain (Table 2). RZPB 1.1 showed to have similarity to $S$. coelicoflavus strain NBRC $15399^{\mathrm{T}}$ (99.59\%) which was isolated from crude oil contaminated soil (Ray et al. 2013). Streptomyces

Table 2. Comparison of $16 \mathrm{~S}$ rRNA gene sequencing identification of culture-dependent endophytic actinobacteria with EzTaxon-e database

\begin{tabular}{|c|c|c|c|c|}
\hline $\begin{array}{l}\text { Isolate } \\
\text { code }\end{array}$ & Species & Strain & $\begin{array}{c}\text { Similarity } \\
(\%)\end{array}$ & $\begin{array}{l}\text { Acession } \\
\text { Number }\end{array}$ \\
\hline \multirow[t]{3}{*}{ RZP 1.3} & S. djakartensis & NBRC $15409^{\mathrm{T}}$ & T 99.19 & AB184657 \\
\hline & S. tuil & NBRC 1 & Т 99.09 & 4690 \\
\hline & S. fumanus & NBRC13042 & 99.09 & AB184273 \\
\hline RZP 1.1 & S. tritolerans & DAS $165^{\mathrm{T}}$ & 99.90 & DQ345779 \\
\hline RZP 2.2 & S. tendae strain & ATCC $19812^{\mathrm{T}}$ & 99.90 & D63873 \\
\hline RZPB 4.1 & S. rubrogriseus & LMG $20318^{\mathrm{T}}$ & 99.90 & AJ781373 \\
\hline RZPB 7.1 & S. fragillis & NRRL 2424T & 99.70 & AY999917 \\
\hline \multirow[t]{2}{*}{ RZPB 1.1} & S. coelicoflavus & NBRC $15399^{\mathrm{T}}$ & T 99.59 & AB1846650 \\
\hline & S. chillikensis & $\mathrm{RC} 1830^{\mathrm{T}}$ & 99.39 & JN050256 \\
\hline
\end{tabular}




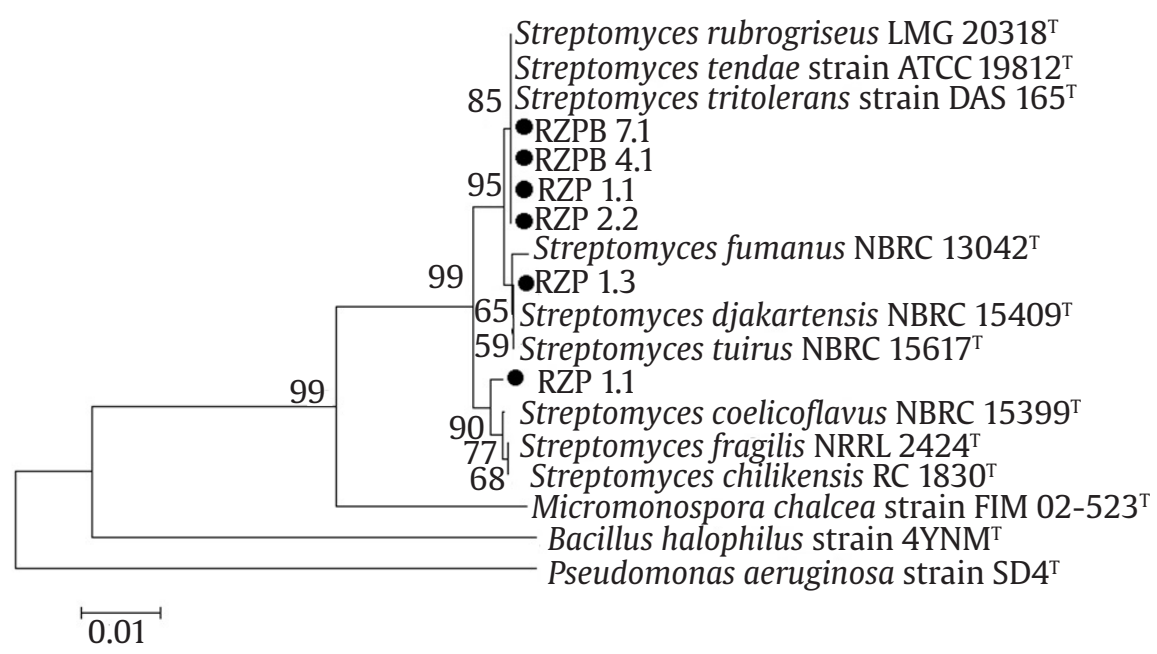

Figure 2. Phylogenetic tree of $16 \mathrm{~S}$ rRNA gene of culture-dependent endophytic actinobacteria constructed using MEGA 6 software

Table 3. Similarity of 16S rRNA gene sequence of culture-independent endophytic actinobacteria to the data base available in EzTaxon-e

\begin{tabular}{|c|c|c|c|c|}
\hline Band & Closest species & Strain & Similarity (\%) & Acession Number \\
\hline \multirow[t]{2}{*}{1} & Agromyces insulae & CFH S0483 $^{\mathrm{T}}$ & 100 & KP232919 \\
\hline & Microbacterium esteraromaticum & DSM 8609 & 99.44 & Y17231 \\
\hline \multirow[t]{2}{*}{2,6} & Microbacterium pseudoresistens & CC-005209 & 100 & FJ865214 \\
\hline & Microbacterium marinilacus & YM11-607 & 100 & AB286020 \\
\hline \multirow[t]{2}{*}{$3,4,5,7$} & Microbacterium testaceum & DSM 20166 & 100 & X77445 \\
\hline & Microbacterium imperiale & DSM $20530^{\mathrm{T}}$ & 100 & X77442 \\
\hline \multirow[t]{2}{*}{8} & Propionibacterium namnetense & NTS31307302 & 96.05 & LWHO01000015 \\
\hline & Cultibacterium acnes & DSM $1897^{\mathrm{T}}$ & 96.05 & AWZZ01000008 \\
\hline \multirow[t]{2}{*}{9} & Streptomyces lushanensis & NRRL B_24994 ${ }^{\mathrm{T}}$ & 98.87 & MAUD01000416 \\
\hline & Streptomyces spongiicola & HNM0071 $^{\mathrm{T}}$ & 98.87 & КT327868 \\
\hline \multirow[t]{2}{*}{10} & Saccharomonospora viridis & DSM $43017^{\mathrm{T}}$ & 93.18 & СР001683 \\
\hline & Nocardia pseudovanccinii & NRRL B-24154 & 93.18 & CLG_48649 \\
\hline \multirow[t]{2}{*}{11,13} & Gordonia kroppenstedtii & NP8- $5^{\mathrm{T}}$ & 99.43 & AM883151 \\
\hline & Mycobacterium pyrenivorans & DSM 44605' & 99.43 & AJ431371 \\
\hline \multirow[t]{2}{*}{12} & Micromonospora rifamycinica & $\mathrm{AM}^{105^{\mathrm{T}}}$ & 96.05 & LRMV01000349 \\
\hline & Actinopolymorpha cephalotaxi & СРCC $202808^{\mathrm{T}}$ & 96.05 & jgi.1085066 \\
\hline
\end{tabular}

coelicoflavus has been known for its potency as a producer of ramnolipid biosurfactants (Kalyani et al. 2014). RZPB 1.1 had similarity to S. coelicoflavus strain NBRC $15399^{\mathrm{T}}$ with spiral of spore chain, with aerial mycelia brown to gray, and yellow to brownish for substrate mycelia (Table 2). Meanwhile, S. coelicoflavus strain NBRC $15399^{\mathrm{T}}$ has greenish white substrate mycelium and light brown to dark brown (Ray et al. 2013). Non actinobacteria, Bacillus halophilus strain 4YNM (Gram +) and Pseudomonas aeruginosa strain SD4 (Gram -) were used as the outer group of the phylogenetic tree.

\subsection{Diversity of Endophytic Actinobacteria Based on a Culture-Independent Approach}

The genomic DNA from leaves and stems of $R$. zoelleri was successfully amplified with the $27 \mathrm{~F}$ and 16Sact1114R as the spesific primers for actinobacteria. The PCR product of 16S rRNA gene of actinobacteria was re-amplified using nested PCR. The nested PCR was carried out by two phases of PCR, the first phase showed to have arround $\pm 1087 \mathrm{bp} 16 \mathrm{~S}$ rRNA gene target. The amplicon was used as a template in the second phase of PCR, to obtain the $\pm 180 \mathrm{bp}$ $16 \mathrm{~S}$ rRNA gene target as V3 region. The 16S rRNA 
gene amplicons were separated using denaturing gradient gel electrophoresis (DGGE) (Figure 5a). There were 13 separate dominant bands in DGGE gel from stems and leaves $R$. zoelleri samples which were successfully isolated by gel cutting. The bands have various sequence homology with Streptomyces and Non-Streptomyces from rare-actinobacteria i.e Agromyces, Gordonia, Microbacterium, Micromonospora, Propionibacterium, Saccharomonospora, Streptomyces (Table 3).

The relative abundance of culture-independent endophytic actinobacterial community from stems and leaves of $R$. zoelleri represented by OTU value can be seen in (Figure 3). One DGGE band represented one OTU or one endophytic actinobacterial community. Table 4 shows the alpha diversity value of stems and leaves, with 9 and 8 OTU, respectively. The OTU 1, 4,6 , and 8 were found in both stem and leaves. The abundance of OTU 1, 4, 6, 8 in stems and leaves were (4,6\%-17.5\%), (7.9\%-15.6\%), (12.2\%), (16.1\%-49.9\%), respectively. OTU 1 similar to Agromyces insulae CFH S0483'. Meanwhile, OTU 4 and 6 have similarty to Microbacterium genus, i.e. M. testaceum DSM 20166T, M. pseudoresistens strain CC-005209T, respectively. OTU 8 has similarity with Propionibacterium namnetense NTS31307302 ${ }^{\mathrm{T}}$. The value of gamma diversity can be interpreted as the number of different communities in each sample. There were 13 of the gamma diversity value found in both stems and leaves. It can be

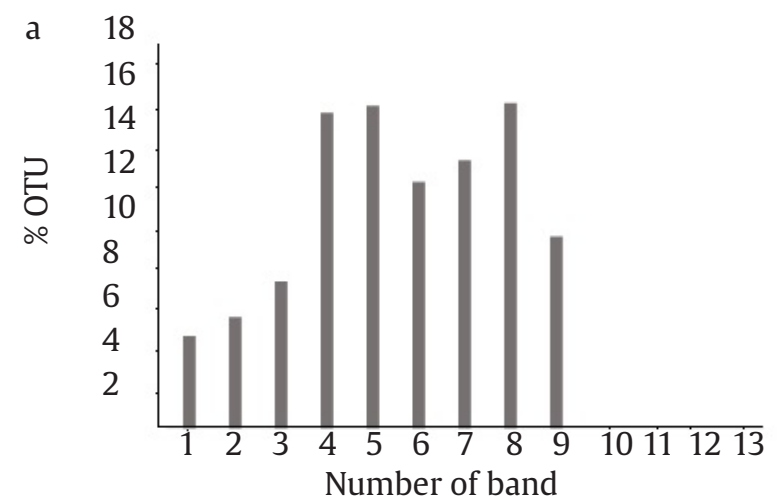

indicated that there were 13 different endophytic actinobacterial communities found in both stems and leaves of $R$. zoelleri.

Shannon Wiener's $\left(\mathrm{H}^{\prime}\right)$ index diversity analysis was used to estimate the diversity of the endophytic actinobacterial community in stems and leaves of $R$. zoelleri. Figure 4 shows that the value of ShannonWienner $\left(\mathrm{H}^{\prime}\right)$ index of endophytic actinobacterial community in stems and leaves ranged from 1.5392.116. The stems show to have higher diversity index than leaves. Category of diversity in stems and leaves of the $R$. zoelleri is still moderate with the range of Shannon index between 1.5 $>\mathrm{H}>3.5$ (Bibi and Ali 2013).

There were 13 bands obtained based on DGGE profile of 16S rRNA gene of actinobacteria $R$. zoelleri (Figure 5a). Phylogenetic analysis based on the $16 \mathrm{~S}$ rRNA gene (Figure 5b) showed that band 1 belonging to genus of Agromyces, and showing the highest similarity to the A. insulae CFH S0483' $(100 \%)$ which was isolated from soil sample of Catba island,Vietnam (Huang et al. 2016). Bands 2 and 6 closed to the genus of Microbacterium especially to the M. pseudoresistens strain CC-005209 (100\%), from Agaricus blazei mushroom stalk (Young et al. 2010). Bands 3, 4, 5, and 7 were afilliated with the genus of Microbacterium, displayed the highest similarity to M. testaceum DSM 20166T (100\%). Band 8 showing low similarities to the genus Propionibacterium, especially with P. namnetense NTS31307302 ${ }^{\mathrm{T}}(96.05 \%)$.

b

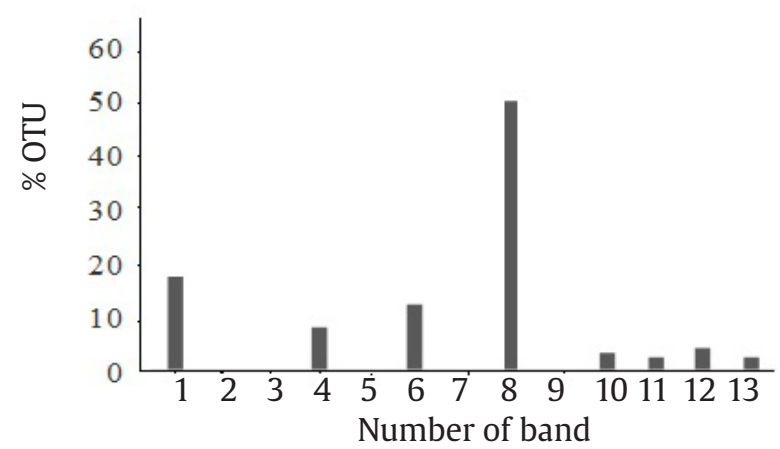

Figure 3. Abundance of endophytes base on OTU found in R. zoelleri tissue, a. stems, b. leaves

Table 4. Abundance of actinobacterial endophyte community found in $R$. zoelleri analysed based on OTU value

\begin{tabular}{lclc}
\hline Sample & Alpha diversity & \multicolumn{1}{c}{$\%$ OTU } & Similar OTU \\
\hline Stems & 9 & $\begin{array}{l}1(4.6 \%), 2(5.5 \%), 3(7.3 \%), 4(15.6 \%), 5(15.9 \%), 6(12.2 \%), \\
7(13.32 \%), 8(16.1), 9(9.5)\end{array}$ & $1,4,6,8$ \\
\hline \multirow{2}{*}{ Leaves } & 8 & $\begin{array}{l}1(17.5 \%), 4(7.9 \%), 6(12.2 \%), 8(49.9 \%), \\
10(3.4 \%), 11(2.2 \%), 12(4.3 \%), 13(2.6 \%)\end{array}$ & $1,4,6,8$ \\
\hline
\end{tabular}


Band 9 from the genus Streptomyces was closely related to S. lushanensis strain of NRRL B_24994 ${ }^{\mathrm{T}}$ (98.87\%). S. lushanensis strain of NRRL B_24994 ${ }^{\mathrm{T}}$ was isolated from soil sample of Lushan Mountain, China (Zang et al. 2015). Band 10 belongs to the genus of Saccharomonospora, with low similarity to the S. viridis DSM 43017 ${ }^{\mathrm{T}}$ (93.18\%). Band 12 had closely related to the genus of Micromonospora, especially with M. rifamycinica $A M 105^{T}$ (96.05\%). Micromonospora rifamycinica $A M 105^{T}$ was isolated from mangrove sediment samples in shouth China Sea (Huang et al. 2008). Bands 11 and 13 from the genus of Gordonia, was closely related to G. kroppenstedtii strain NP8-5 (99.43\%), isolated from a polluted steam in Gumil, Korea (Kim et al. 2009).

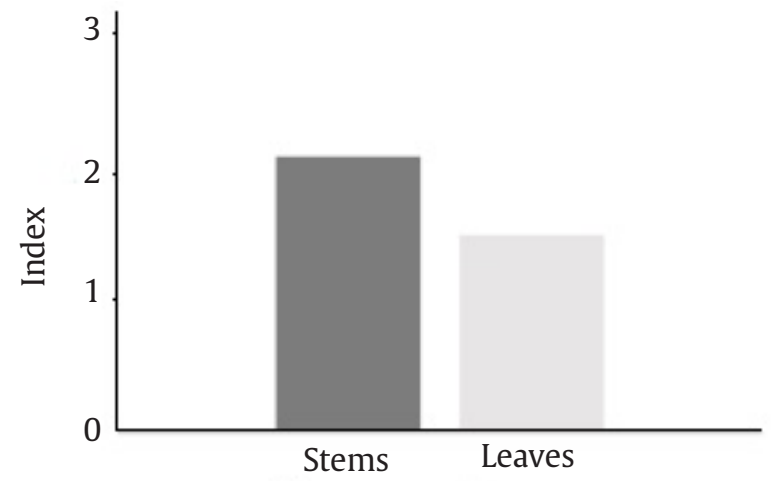

Figure 4. Alpha diversity (Shannon-Wienner) of endophytic actinobacterial community found in $R$. zoelleri

\section{Discussion}

\subsection{Culturable Endophytic Actinobacteria by a Culture-Dependent Approach}

This is the first report on the existence of endophytic actinobacteria found in $R$. zoelleri leaves and stems. Based on culture-dependent approach, there were six isolates of endophytic actinobacteria found. Their morhological characters indicated that all isolates close to the groupped of Streptomyces (Shirling and Gottlieb 1966). The six isolates (RZP 1.3, RZP 1.1, RZP 2.2, RZPB 1.1, RZPB 7.1, RZPB 4.1) had vary of mycelia substrate, mycelia aerial, and media pigmentation on ISP 2, ISP 3, ISP 4, YSA medium. According to Reddy et al. (2011), the same isolates showed vary in colors of mycelia substrate, mycelia aerial, media pigmentation, when grown on different medium. The isolate of RZP 1.3, RZP 1.1, RZP 2.2, RZPB 1.1, RZPB 7.1, RZPB 4.1 indicated as Streptomyces, based on their morphological characters.

Under a culture-dependent approach, the dominance of Streptomyces may be caused by HV medium used during cultivation, which may be more preference for Streptomyces group to grow compared to the non-Streptomyces group. The existence of culturable endophytic actinobacteria $R$. zoelleri can be explored further using various growth media. Humic AcidVitamin Agar was a selective medium for growth of large number of actinobacteria. HV agar containing of humic acid used as sole source of energy and nitrogen. In addition, humic acid initiated the occurrence of sporulation (Hayakawa and Nonomura 1987). The growth

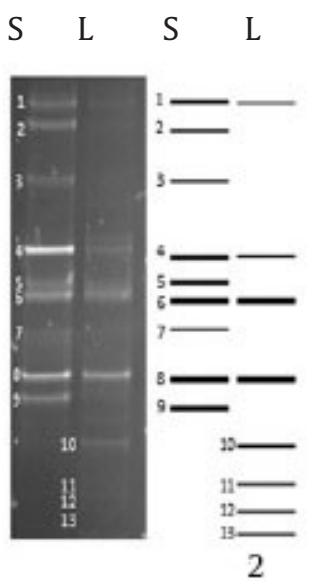

a

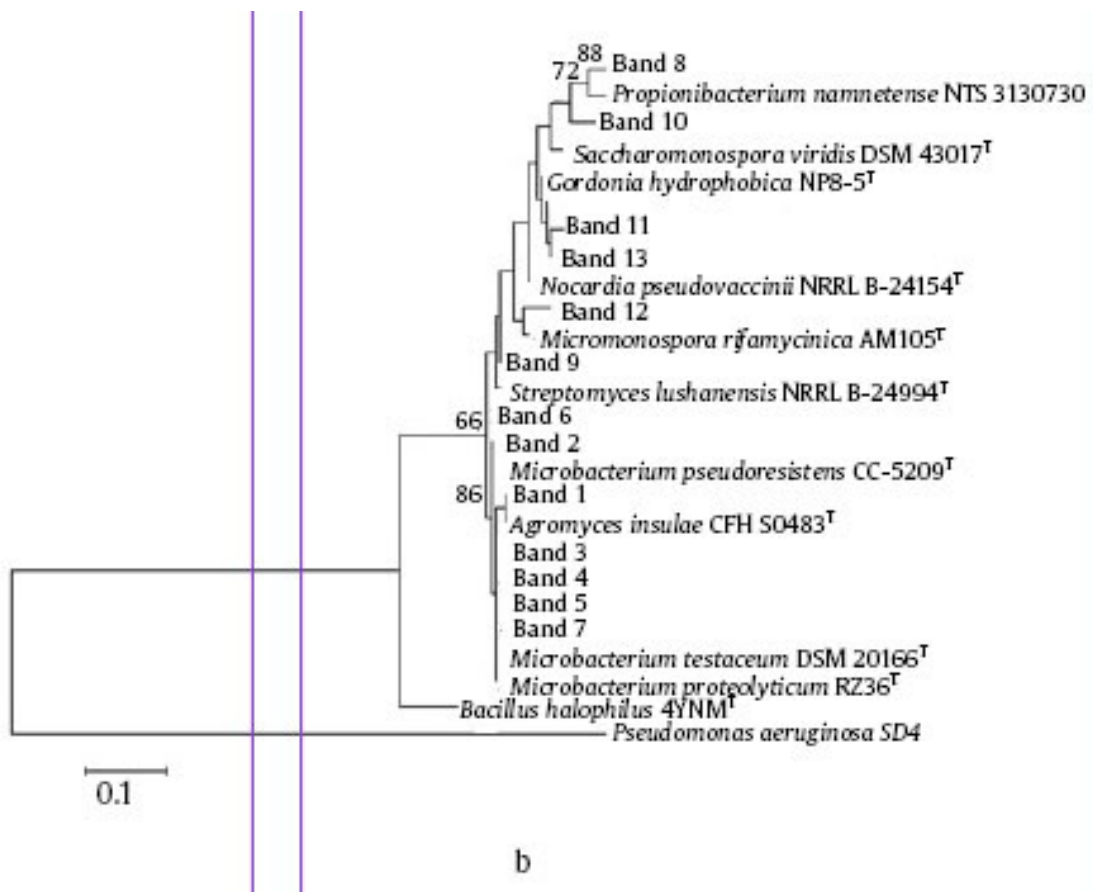

Figure 5. a) 1) DGGE profile of 16S rRNA gene samples $R$. zoelleri, 2) llustration band of DGGE using Cliqs ID software, stems (S), Leaves (L). b) Phylogenetic tree based on DDGE separation of 16S rRNA gene of culture-independent endophytic actinobacteria, was constructed using MEGA 6 software 
development of Streptomyces can also be influenced by $\mathrm{pH}$ and temperature (Oskay 2009).

Phylogenetic analysis based on 16S rRNA gene partial sequence indicated that six isolates were in one cluster (Streptomyces) (Figure 2) and showed high similarity ranging from 99.09-99.90\%. The highest similarity of the $16 S$ rRNA gene sequence to the comparable sequence, still can be characterized further for the possibility to find novel species by considering different and unique characters of isolate. It can be further examined using the polyphasic taxonomic approach. Lisdiyanti et al. (2010) reported three novel spesies from six Indonesia strains with the highest simililarity to the other known strain in the genus of Actinokineospora ranging from 9799.4\%. Other report from Otoguro et al. (2011) showed that two isolates that proposed as novel species in the genus of Actinophytocola, have 98.1-98.2\% similarity to the reference strain.

\subsection{Communities of Endophytic Actnobacteria by a Culture-Independent Approach}

Based on direct observation and considering the position of the band of DGGE (band with the same positions taken one) there were 13 separate dominant bands. The analysis of total of separated band using software Cliqs $1 D$, detected 9 bands from stems and 8 bands from leaves. Endophytic actinobacteria which reside in stems found to be slightly more diverse than leaves. Qin et al. (2012) reported that by metagenomic analysis, there were 240 clones of endophytic actinobacteria from stems and 213 clones from leaves. It seems likely that endophytic actinobacteria have preference and can reside in spesific tissues.

The 13 OTUs obtained from stems and leaves indicate that $R$. zoelleri may have 13 different endophytic actinobacterial communities which reside in stem and leave tissues. Based on reference data available in the gene bank, the 13 OTUs have similarity with the genus of Agromyces, Gordonia, Microbacterium, Micromonospora, Propionibacterium, Saccharomonospora, Streptomyces. There were 4 OTUs that always exist in stems and leaves of $R$. zoelleri i.e. OTU 1 , OTU 4, OTU 6 , and OTU 8 , and based on reference data in gene bank, these 4 OTUs similar with Agromyces insulae, Microbacterium testaceum, M. pseudoresistens, Propionibacterium namnetense, respectively. There were diferences in endophytic actinobacteria diversity observed between culturable and culture-independent approaches. The culturable approach found only one genus of actinobacteria i.e. Streptomyces. Meanwhile, both Streptomyces and non Streptomyces were observed using cultureindependent approach. Based on the Shannon $\left(\mathrm{H}^{\prime}\right)$ index, the diversity of actinobacteria in stems and leaves of $R$. zoelleri was in the medium category
(1.539-2.116). Stem has the highest diversity index (1.539), while leave has the lowest diversity index (2.116). Plant tissue is considered as a very selective habitat, not all bacterial communities can survive in all plant tissue. According to Passari et al. (2015), endophytic actinobacteria could colonize different spesific tissues of host plants, indicated their diversity amongst different tissues.

Phylogenetic analysis showed that 13 DNA bands of culture-independent endophytic actinobacteria were affiliated with both Streptomyces and NonStreptomyces from rare-actinobacteria namely Agromyces, Gordonia, Microbacterium, Micromonospora, Propionibacterium, Saccharomonospora, Streptomyces with $93.18-100 \%$ similarity compare to the reference strain in EzTaxon-e. Agromyces, Microbacterium, Micromonospora, Propionibacterium were observed to be predominat in stems and leaves of $R$. zoelleri. Tian et al. (2007) reported that S. gailaeus was detected as high abundance in rice tissues. It was discovered in rice stems and roots, and some endophytic actinobacteria populations correlated with host plant tissues.

\subsection{Comparison between Community of Endophytic Actinobacteria by Culture-Dependent and Culture-Independent Approaches}

There were diversity diferences between culturable actinobacteria and the culture-independent endophytic actinobacteria from $R$. zoelleri. Culture-dependent approach, that was conducted by isolating and cultivating endophytic actinobacteria in HV agar medium, recovered isolates from single genus i.e. Streptomyces. Whereas the culture-independent, as metagenomic approach, amplifying $16 \mathrm{~S}$ rRNA gene of actinobacteria and using DGGE method, found both Streptomyces and Non- Streptomyces from rare-actinobacteria, There are 7 genera obtained i.e. Agromyces, Gordonia, Microbacterium, Micromonospora, Propionibacterium, Saccharomonospora, Streptomyces.

Based on the data comparison, the culture-independent approach using DGGE, give more information about community profile of endophytic actinobacteria than the culture-dependent approach. Combining both of culturedependent and culture-independent approaches can be a good strategy to study the existence of actinobacterial community who reside in their host plant tissue of $R$. zoelleri.

\section{Acknowledgements}

The authors would like to thanks the Cibodas Botanical Garden, as a national plant conservation area in Indonesia, for giving sample of $R$. zoelleri. Part of the research activity was financially supported by Lembaga Pengelolaan Dana Pendidikan (LPDP) given to Lia Aseptin Murdini, and the research work also partly supported by decentralization research scheme (PUPT) awarded to Yulin lestari. 


\section{References}

Argent G. 2006. Rhododendrons of subgenus Vireya. Cambrige Univ Press.

Bibi F, Ali Z. 2013. Measurement of diversity indices of avian communities at taunsa barrage wildlife sanctuary, Pakistan. J Anim Plant Sci 23:201367.

Choi YH et al. 2012. Rhododendric acid A, a new ursanetype PTP1B inhibitor from the endangered plant Rhododendron brachycarpum G. Don. Bioorg Med Chem Lett 22:6116-6119.

Coombs JT, Franco CMM. 2003. Isolation and identification of actinobacteria from surface-sterilized wheat roots. Appl Environ Microbiol 69:5603-5608.

Emley TM, Stackebrandt E. 1994. The molecular phylogeny and systematics of the actinomycetes. Annu Rev Microbiol 48:257-289.

Hayakawa M, Nonomura. 1987. Humic acid-vitamin agar, a new medium for the selective isolation of soil actinomycetes. J Ferment Technol 65:501-509.

Hill TCJ et al. 2003. Using ecological diversity measures with bacterial comunities. FEMS Microbiol Ecol 43:1-11.

Huang JR et al. 2016. Agromyces insulae sp. nov., an actinobacterium isolated from a soil sample. Int J Syst Evol Microbiol 66:2002-2007.

Huang $\mathrm{H}$ et al. 2008. Micromonospora rifamycinica sp. nov., a novel actinomycete from mangrove sediment. Int J Syst Evol Microbiol 58:17-20.

Kalyani ALT et al. 2014. Production optimization of rhamnolipid biosurfactant by Streptomyces coelicoflavus (NBRC 15399) using plackett-burman design. Eur J Biotechnol Biosci 1:07-13.

Kim KK et al. 2009. Gordonia kroppenstedtii sp. nov., a phenoldegrading actinomycete isolated from a polluted stream. Int J Syst Evol Microbiol 59:1992-1992.

Kimura N. 2006. Metagenomics: Access to unculturable microbes in the environment. J Microbes Environ 21:201-215.

Leduc C et al. 2006. Plants used by the cree nation of eeyou istchee (Quebec, Canada) for the treatment of diabetes: a novel approach in quantitative ethnobotany. J Ethnopharmacol 105:55-63.

Lisdiyanti P et al. 2010. Actinokineospora baliensis sp. nov., Actinokineospora cibodasensis sp. nov. and Actinokineospora cianjurensis sp. nov., isolated from soil and plant litter. Int J Syst Evol Microbiol 60:2331-2335.

Mangamuri UM et al. 2014. Optimization of process parameters for improved production of bioactive metabolites by Streptomyces tritolerans DAS $165^{\mathrm{T}}$. Brit Microbiol Res J 4:428-442.

Martina Ket al. 2008. Development of a 16S rRNA gene based prototype microarray for the detection of selected actinomycetes genera. Anton Leeuw Int J G 94:439-453.

Muyzer G, Uitterlinden AG. 1993. Profiling of complex microbial populations by denaturing gradien gel electrophoresis analysis of polymerase chain reaction-amplified genes coding for 16S rRNA. Appl Environ Microbiol 59:695-700.

Otoguro M et al. 2011. Actinophytocola timorensis sp. nov. and Actinophytocola corallina sp. nov., isolated from soil. Int J Syst Evol Microbiol 61:834-838.
Oskay M. 2009. Comparison of Streptomyces diversity between agricultural and non-agricultural soils by using various culture media. Sci Res Ess 4:997-1005.

Overeas L et al. 1997. Distribution of bacterioplankton in meromictic Lake Saelevannet, as determined by denaturing gradien gel electrophoresis of PCR amplified gene fragmens coding for 16S rRNA. Appl Environ Microbiol 63:3367-3373.

Passari AK et al. 2015. Isolation, abundance and phylogenetic affiliation of endophytic actinomycetes associated with medicinal plants and screening for their invitro antimicrobial biosynthetic potential. Front Microbiol 6:273-285.

Pujiyanto S et al. 2012. Alpha-glucosidase inhibitor activity and characterization of endophytic actinomycetes isolated from some indonesian diabetic medicinal plants. Int J Pharm Pharm Sci 4:327-333.

Qiang Y et al. 2011. Chemical constituents of plants from the genus Rhododendron. Chem Biodivers 8:792-815.

Qin S et al. 2012. Abundant and diverse endhophytic actinobacteria associated with medicial plant Maytenus austroyunnanensis in Xishuangbanna tropical rain forest revealed by culture-dependent and culture-independent methods. Environ Microbiol 4:522-531.

Ray R et al. 2013. Streptomyces chilikensis sp. nov., a halophilic streptomycete isolated from brackish water sediment. Int J Syst Evol Microbiol 63:2757-2764.

Reddy TVK et al. 2011. Streptomyces hyderabadensis sp .nov. an actinomycete isolated from soil. Int J Syst Evol Microbiol 61:76-80.

Schulz B et al. 1993. Endophytes from herbaceous plants and shrubs: effectiveness of surface sterilization methods. Mycol Res 97:1447-1450.

Shirling EB, Gottlieb D. 1966. Methods for characterization of Streptomyces species. Int J Syst Bacteriol 16:313-340.

Syed DG et al. 2007. Streptomyces tritolerans sp. nov., a novel actinomycete isolated from soil in Karnataka, India. Anton Leeuw Int J G 92:391-397.

Tamura K et al. 2011. MEGA 5: molecular evolutionary genetics analysis using maximum likehood, evolutionary distance, and maximum parsimony methods. Mol Biol Evol 28:2731-2739.

Tam TW et al. 2011. Cree antidiabetic plant extracts display mechanism-based inactivation of CYP3A4. Can J Physiol Pharmacol 89:13-23.

Tan RX, Zou WX. 2001. Endophytes: a rich source of functional metabolites. Nat Prod Rep 18:448-459.

Tian X et al. 2007. Diversity of cultivated and uncultivated actinobacterial endophytes in the stems and roots of rice. Microb Ecol 53:700-707.

Young CC et al. 2010. Microbacterium agarici sp. nov., Microbacterium humi sp. nov. and Microbacterium pseudoresistens sp. nov., isolated from the base of the mushroom Agaricus blazei. Int J Syst Evol Microbiol 60:854-860.

Zhao K et al. 2011. The diversity and anti-microbial activity of endophytic actinomycetes isolated from medicinal plants in panxi plateau. Curr Microbiol 62:182-190.

Zhang BH et al. 2015. Streptomyces lushanensis sp. nov., a novel actinomycete with anti-cyanobacterial activity. J Antibiot 68:5-8. 